\title{
Caffeine Residue in Terengganu River Basins in Malaysia: Distribution and Risk Assessment
}

\author{
Wan Mohd Afiq Wan Mohd Khalik*(**)†, Saw Hong Loh*, Haslina Albani*, Siti Aisyah Syazwani Alias* and \\ Khaeriah Ulfah Rahman* \\ *Faculty of Science and Marine Environment, Universiti Malaysia Terengganu, 21030, Kuala Nerus, Malaysia \\ **Centre for Water Research and Analysis, Faculty of Science and Technology, Universiti Kebangsaan Malaysia, \\ 43600, Bangi, Malaysia \\ †Corresponding author: Wan Mohd Afiq Wan Mohd Khalik; wan.afiq@umt.edu.my
}

Nat. Env. \& Poll. Tech. Website: www.neptjournal.com

Received: 09-06-2019

Accepted: 30-08-2019

Key Words:

Emerging contaminant;

Stimulant drug;

Risk quotient;

Pharmaceutical residue

\begin{abstract}
The occurrence of caffeine residue in Malaysian waters was successfully studied. The micropollutant abundance was recorded for three selected main rivers namely Terengganu, Ibai and Setiu which are located in Terengganu, Peninsular Malaysia. Surface water samples were taken twice in September and November 2018 from 15 sampling stations. Caffeine residue was determined using the solid phase extraction technique followed by a final analysis using a high performance liquid chromatography-UV detector. Measured concentration levels ranged from 384 to $426 \mathrm{ng} / \mathrm{L}$ for both datasets obtained from the two sampling surveys. The ecological risk assessment was calculated to be at low risk ranging from $R Q 0.075$ to 0.085 , while the risk quotients (RQ) of human health risk was recorded below than 0.20 for three life-stage categories. The MaxRI values fall under class II which means that there is a risk of sublethal effects to aquatic organisms.
\end{abstract}

\section{INTRODUCTION}

Caffeine is classified as a non-prescription stimulant and psychoactive substance. The global average consumption of caffeine is estimated to be in the range of 80 to $400 \mathrm{mg}$ per person per day. Humans excrete approximately 0.5 to $10 \%$ of unchanged caffeine through urine and faeces (Edward et al. 2015). The main sources of caffeine in environmental waters are primarily anthropogenic and are often detected in wastewater. Caffeine has high solubility $\left(13.5\right.$ g.L $\left.\mathrm{L}^{-1}\right)$ but negligible volatility in water. It has gained attention since its presence in environmental waters is ubiquitous, human-related, source-specific and released in significant quantities. Caffeine has thus become suitable as a chemical marker for river and groundwater pollution; this fact has been well-documented in past literature (Buerge et al. 2003, Ferreira 2005, Wu et al. 2008, Yang et al. 2017). Caffeine has a half-life of 30 days in natural environments and up to 100 days in estuarine waters (Cantwell et al. 2016).

The possibility of chronic or acute toxicity in aquatic organisms due to long-term exposure to pharmaceutically active compounds, including caffeine has become of great concern. The risk quotient $(\mathrm{RQ})$ is a mathematical approach to express the ecological risk of a stressor in the environment at low-level concentrations (Ramaswamy et al. 2011, Guzel et al. 2018). In terms of risk to human health, the quotient value is associated with the level of human exposure to contaminated water. The calculation may express the posed threat of a single or a mixture of contaminants. The interpolated data is then scaled into a numerical range; the common rule is RQ> 1 which signifies the high potential of environmental risk.

To calculate the ecological risk or human health risk from contaminants like caffeine, the baseline data are designated as latent information. However, there is limited documentation on the distribution and risk assessment of caffeine reported in Malaysian rivers. Only two previous studies have performed a risk assessment in west Peninsular Malaysia, namely the Lui River and Selangor River (Praveena et al. 2018) and the Klang River (Subari et al. 2017). To date, no scientific document on pharmaceutical residue has been reported for the east coast of Peninsular Malaysia. Indeed, this research work takes the initiative to report the existence of pharmaceutical residue in Terengganu rivers by using caffeine as the subject of study. As caffeine may pose ecotoxicological and human health risks, the RQ analysis was performed to assess the potential environmental risk on both aquatic organisms living underwater and humans who use these rivers as their source of drinking water.

\section{MATERIALS AND METHODS}

\section{Chemical}

Highly pure caffeine was purchased from Sigma-Aldrich in 
St Louis. The standard solution was dissolved in methanol solution to construct a series of working solutions. Liquid chromatography grade solvents (acetone, methanol, methyl tert-butyl ether) were used for sample preparation and analysis.

\section{Study Area}

This study chose to focus on Terengganu, one of the states located in Peninsular Malaysia. Terengganu is located in the east coast region and is adjacent to Kelantan and Pahang on its northern and southern sides, respectively. The Terengganu River and Ibai River are situated in Kuala Terengganu (Laila et al. 2018). Both rivers flow through Terengganu's main capital where many major developments close to the coastal zone are located. Domestic industries and human settlements are the major activities located close to the Terengganu and Ibai Rivers (Suratman et al. 2015). Meanwhile, the Setiu River is situated in Setiu which is a district in the northern part of Terengganu. It is considered as a rural area; thus, water from the river plays a significant role in the livelihood of the population as their source of water for daily use, aquaculture and agriculture (Zaideen et al. 2017).

\section{Sampling Activity}

Water samples were taken twice in September and November 2018. Fifteen sampling stations were designated as locations to study the anthropogenic impact of the nearby riverine systems. The coordinates for each station were taken using a handheld GPS and tabulated in Table 1 and Fig. 1, respectively. 1-L grab surface water samples were taken using high-density polyethylene (HDPE) bottles. Separate water samples were also collected in 500-mL quantities for physicochemical water analysis (ammoniacal-nitrogen, biochemical oxygen demand, and suspended solids). The rinsed bottles were submerged below the water surface and filled up to full capacity before immediately capped underwater and kept in a cooler until ready for analysis. In-situ parameters namely $\mathrm{pH}$, dissolved oxygen, temperature, salinity and conductivity were recorded using a YSI 660 hydrolab multiparameter.

\section{Laboratory Analysis}

Caffeine residue was extracted using the solid phase extraction technique, Oasis HLB cartridge $500 \mathrm{mg} 6 \mathrm{cc}$ (Waters, Milford). The procedure for caffeine analysis was adapted from the researchers' previous method (Al-Qaim et al. 2017). Samples were pre-filtered using a GF/C glass microfiber filter 0.7- $\mu \mathrm{m}$ (Whatman, Buckinghamshire) to remove the suspended matter. The cartridges were conditioned with 2-mL methyl tert-butyl ether, 2-mL methanol and 2-mL deionised water, respectively. $250-\mathrm{mL}$ water samples were loaded continuously at a controlled flow rate of $2.0 \mathrm{~mL} \cdot \mathrm{min}^{-1}$ using the vacuum system. The cartridges were later washed using 2-mL deionised water. The enrich sample was extracted

Table 1: The coordinates of sampling location in Terengganu rivers, Malaysia.

\begin{tabular}{|c|c|c|c|}
\hline River & Station Code & Latitude (N) & Longitude (E) \\
\hline \multirow[t]{5}{*}{ Ibai } & S1-Ibai & $5^{\circ} 17^{\prime} 03.3^{\prime \prime}$ & $103^{\circ} 10^{\prime} 13.5^{\prime \prime}$ \\
\hline & S2-Ibai & $5^{\circ} 16^{\prime} 43.9^{\prime \prime}$ & $103^{\circ} 10^{\prime} 06.0$ " \\
\hline & S3-Ibai & $5^{\circ} 16^{\prime} 38.0^{\prime \prime}$ & $103^{\circ} 09^{\prime} 20.6 "$ \\
\hline & S4-Ibai & $5^{\circ} 16^{\prime} 11.4^{\prime \prime}$ & $103^{\circ} 08^{\prime} 59.4^{\prime \prime}$ \\
\hline & S5-Ibai & $5^{\circ} 16^{\prime} 49.3^{\prime \prime}$ & $103^{\circ} 08^{\prime} 31.2^{\prime \prime}$ \\
\hline \multirow[t]{5}{*}{ Setiu } & S1-Setiu & $5^{\circ} 38^{\prime} 26.6^{\prime \prime}$ & $102^{\circ} 46^{\prime} 32.6 "$ \\
\hline & S2-Setiu & $5^{\circ} 36^{\prime} 50.2^{\prime \prime}$ & $102^{\circ} 48^{\prime} 22.1^{\prime \prime}$ \\
\hline & S3-Setiu & $5^{\circ} 36^{\prime} 14.9^{\prime \prime}$ & $102^{\circ} 48^{\prime} 52.8^{\prime \prime}$ \\
\hline & S4-Setiu & $5^{\circ} 35^{\prime} 14.1 ”$ & $102^{\circ} 46^{\prime} 42.3^{\prime \prime}$ \\
\hline & S5-Setiu & $5^{\circ} 34^{\prime} 45.2^{\prime \prime}$ & $102^{\circ} 46^{\prime} 09.8^{\prime \prime}$ \\
\hline \multirow[t]{5}{*}{ Terengganu } & S1-Terengganu & $5^{\circ} 19^{\prime} 22.8^{\prime \prime}$ & $103^{\circ} 07^{\prime} 27.4 "$ \\
\hline & S2-Terengganu & $5^{\circ} 19^{\prime} 24.4^{\prime \prime}$ & $103^{\circ} 06^{\prime} 58.6^{\prime \prime}$ \\
\hline & S3-Terengganu & $5^{\circ} 19^{\prime} 26.5^{\prime \prime}$ & $103^{\circ} 05^{\prime} 58.8^{\prime \prime}$ \\
\hline & S4-Terengganu & $5^{\circ} 17^{\prime} 55.3^{\prime \prime}$ & $103^{\circ} 05^{\prime} 14.6 "$ \\
\hline & S5-Terengganu & $5^{\circ} 17^{\prime} 15.9^{\prime \prime}$ & $103^{\circ} 05^{\prime} 40.6^{\prime \prime}$ \\
\hline
\end{tabular}




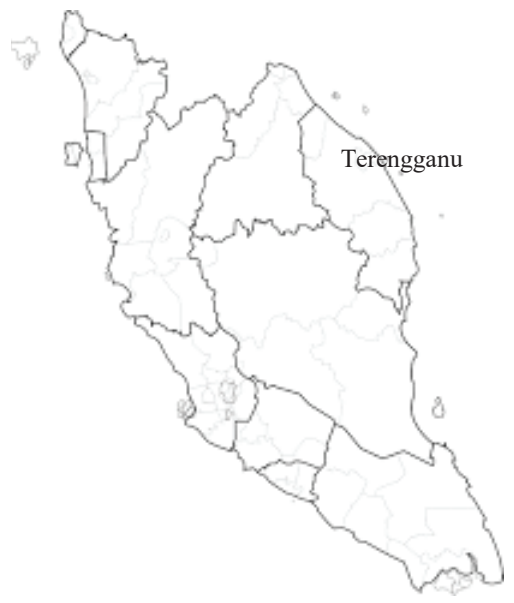

Peninsular Malaysia
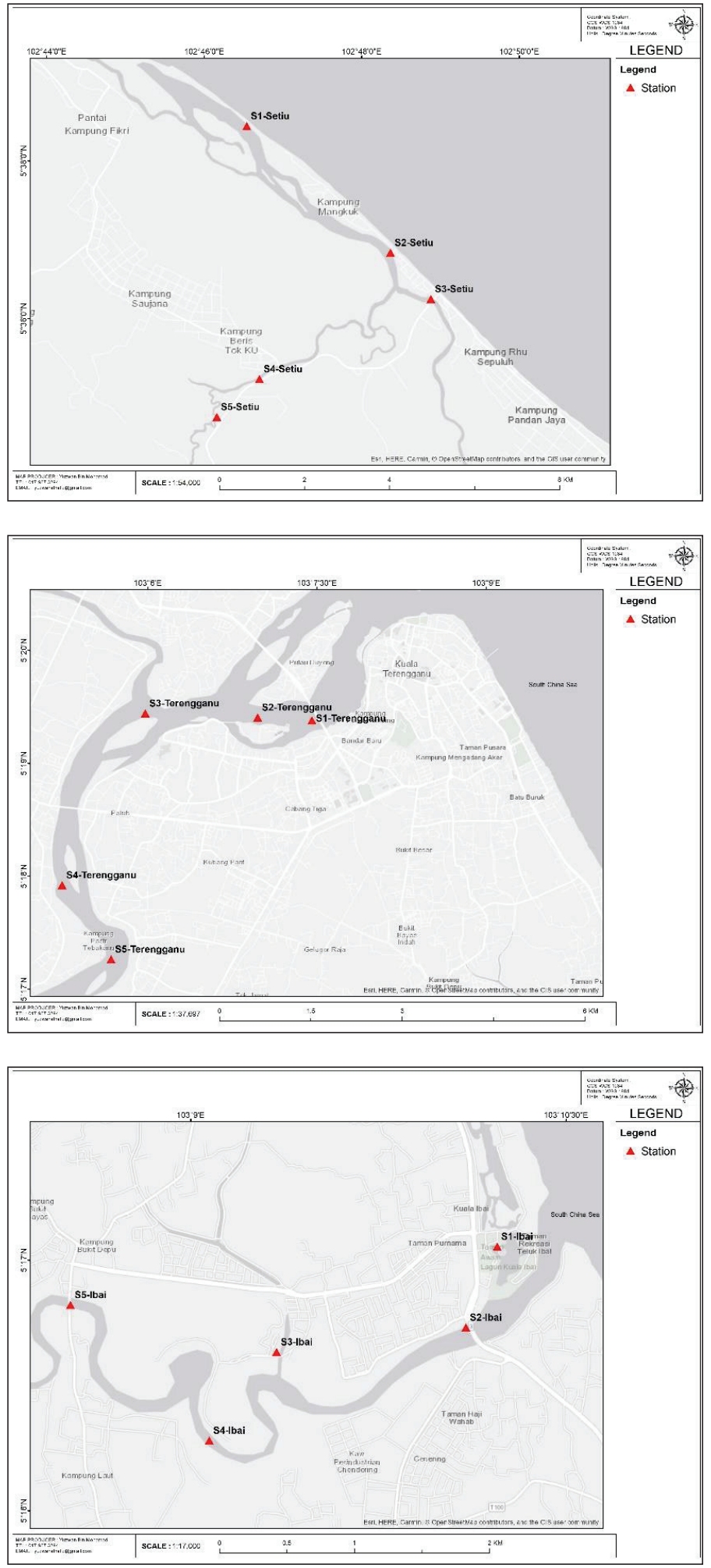

Fig. 1: The map of sampling stations located in Terengganu, Malaysia. 
from the sorbent using 2-mL methyl tert-butyl ether, 2-mL acetone and 3-mL methanol, respectively. Later, the solution was concentrated in a vacuum concentrator till a final volume of $1-\mathrm{mL}$ was obtained.

Before chromatographic analysis, the sample extracts were filtered through a $0.45-\mu$ m nylon syringe filter. The final extracts were analysed using a High Performance Liquid Chromatography-UV detector (Shimadzu, Kyoto) equipped with an Apollo $\mathrm{C}_{18}(250 \mathrm{~mm} \times 4.6 \mathrm{~mm}, 5 \mu \mathrm{m})$ GraceTM column. The mobile phase composition is methanol and deionised water at a ratio of $65: 35$ in the isocratic mode. The flow rate was controlled at $1.5 \mathrm{~mL} \cdot \mathrm{min}^{-1}$. The wavelength for caffeine compound was set at $273 \mathrm{~nm}$. The retention time for caffeine was achieved at 3.0 minutes with a total runtime of 4 minutes. The injection loop of the sample was $20-\mu \mathrm{L}$ for every injection. Quantitative analyses were performed using external calibration standards. The calibration graph was constructed using concentration levels ranging from 0.1 ng. $\mathrm{mL}^{-1}-1 \mu \mathrm{g} \cdot \mathrm{mL}^{-1}\left(\mathrm{r}^{2}=0.996\right)$. The instrument detection limit was $0.014 \mathrm{ng} \cdot \mathrm{mL}^{-1}$.

The identification of caffeine in river waters was also conducted using gas chromatography-mass spectrometry. One sample from each river was used as representative of the total samples. The settings selected for the gas chromatography are as follows: injection temperature and detector at 250 and $220^{\circ} \mathrm{C}$ respectively; oven programme maintained at $200^{\circ} \mathrm{C}$ for 1.5 minutes, then ramped at $30^{\circ} \mathrm{C} /$ minutes to $275^{\circ} \mathrm{C}$, column flow was $1 \mathrm{~mL} \mathrm{m^{-1 }}$; retention time and run time analysis are 7.24 and 13.4 minutes, respectively; and mass range was scanned from 50 to $300 \mathrm{~m} / \mathrm{z}$. The extracted mass chromatogram of caffeine was $194 \mathrm{~m} / \mathrm{z}$ as elucidated from the NIST11 library.

The level of ammoniacal nitrogen was determined using the $4500-\mathrm{NH}_{3}$ phenate method, while the final analysis was carried out using a Carry $50 \mathrm{UV}$-Vis spectrophotometer (Varian, Palo Alto). The peak spectra were recorded at $640 \mathrm{~nm}$ and the scan rate was controlled at $10 \mathrm{~nm} \mathrm{~s}^{-1}$. The ammonia reacted with phenol to form indophenol in the presence of an alkali and an oxidising agent. Sodium nitroprusside served as a catalyst. The total suspended solids were calculated using the gravimetric method. The 500-mL water samples were filtered through a $0.7 \mu \mathrm{m}$ glass fibre filter (Whatman, Buckinghamshire). The filter was dried at $102^{\circ} \mathrm{C}$ till a constant weight was obtained. The weight difference between the dry filter after filtering and the clean filter was expressed as the weight of the suspended solids.

\section{Statistical Analysis}

Statistical analyses were conducted using Minitab Version
17.0 (Minitab Inc., Pennsylvania) to identify the significant differences and relationship between caffeine and water quality. In this work, the hierarchal cluster analysis was implemented using Ward's hierarchical agglomerative method of clustering and Euclidean distance measure to analyse the relationship between caffeine and water quality of the studied rivers.

The risk quotient (RQ) was used to assess the ecological risk of caffeine in the selected Terengganu rivers. The equation is expressed as follows:

$$
R Q_{M E C}=\frac{M E C}{P N E C}
$$

Where, $M E C$ is the measured environmental concentration and $P N E C$ is the predicted no-effect concentration. The lowest $P N E C$ value for caffeine in water was obtained from literature, 5000 ng.L $\mathrm{L}^{-1}$ (He et al. 2018). The RQ measure was scaled as follows: $>1.0$ (high), 0.1-1.0 (medium), and 0.01-0.1 (low).

For human health, the risk assessment was calculated as the worst-case scenario if the water was used as a source of drinking water. The formula used is expressed as Equation 2 below:

$$
R Q=\frac{M C}{D W E L}
$$

Where, $M C$ is defined as the maximum measured concentration and $D W E L$ is the age-dependent drinking water equivalent level. DWEL was estimated for three age categories using the formula expressed below:

$$
D W E L=\frac{A D I X B W}{D W I X A B X F O E}
$$

Where, $A D I$ is the average daily intake ( $\mu \mathrm{g} / \mathrm{kg} / \mathrm{day})$. The value for ADI of caffeine (150) was adopted from literature. $B W$ is the median body weight $(\mathrm{kg})$ of the age-specific groups. $D W I$ is the daily drinking water intake (L/day) of the age-specific groups. $A B$ is the gastrointestinal absorption rate, which was assumed to be 1 , while FOE is the frequency of exposure which was put as 365 days (Sharma et al. 2018). The method reporting limit was calculated at $21.20 \mu \mathrm{g} . \mathrm{L}^{-1}$.

The risk index was calculated using Equation 4 as expressed below:

$$
\left[\sum_{i=1}^{n}(T o x j, k \div M E C j, k) i\right]_{x} 0.1
$$

Where, $i$ is defined as selected pharmaceutically active compounds, $j$ is sampling site, $k$ is sampling date, and Tox $j, k$ is acute toxicity for pharmaceutically active compounds (Fernández et al. 2010). In this case, the compound refers to the measured total concentration of caffeine. 
Table 2: Physico-chemical data of water quality recorded in Terengganu rivers.

\begin{tabular}{|lllllcc|}
\hline \multirow{2}{*}{ Parameter } & \multicolumn{2}{c}{ Terengganu River } & \multicolumn{3}{c}{ Ibai River } & Metiu River \\
\cline { 2 - 6 } & Range & Mean & Range & Mean & Range \\
\hline Water pH & $6.23-6.90$ & $6.58 \pm 0.22$ & $6.01-7.53$ & $6.83 \pm 0.50$ & $4.04-7.89$ & $5.79 \pm 1.07$ \\
Water temperature & $19.50-29.40$ & $25.47 \pm 4.28$ & $22.70-29.20$ & $26.10 \pm 3.15$ & $28.60-29.80$ & $29.81 \pm 0.50$ \\
Dissolved oxygen & $6.55-8.19$ & $7.31 \pm 0.59$ & $1.90-7.12$ & $5.11 \pm 1.50$ & $5.20-7.06$ & $6.56 \pm 0.54$ \\
Suspended solids & $12.01-84.40$ & $46.12 \pm 22.28$ & $16.80-70.80$ & $39.84 \pm 19.25$ & $18.00-54.80$ & $39.44 \pm 13.09$ \\
Biochemical oxygen demand & $1.84-5.04$ & $3.14 \pm 1.02$ & $3.65-5.59$ & $4.76 \pm 0.86$ & $4.85-7.01$ & $6.41 \pm 0.71$ \\
Ammoniacal nitrogen & $0.01-0.20$ & $0.07 \pm 0.06$ & $0.03-0.16$ & $0.06 \pm 0.03$ & $0.02-0.16$ & $0.05 \pm 0.04$ \\
\hline
\end{tabular}

Unit expressed as mg. $\mathrm{L}^{-1}$ except for temperature $\left({ }^{\circ} \mathrm{C}\right)$

\section{RESULTS AND DISCUSSION}

\section{Water Chemistry}

The $\mathrm{pH}$ values of the river waters were recorded to have acidic characteristics. This fact is not only recorded in this study, but the trend has been well-documented in past literature for all rivers studied. For example, studies conducted by Suratman et al. (2015) and Laila et al. (2018) recorded $\mathrm{pH}$ values of less than 7 with mean values of 6.37 and 6.62 for Terengganu River and Ibai River, respectively. The level of dissolved oxygen content in upstream locations was found to be higher compared to downstream areas. It is believed that the anthropogenic input from development works in downstream areas have caused this situation. The Terengganu river revealed higher organic content present in comparison to the Ibai River and Setiu River. This pattern has been predicted on the back of the high level of urbanisation in this area which has caused more pollutants to be introduced into the river basin. In line with this finding, the biochemical oxygen demand recorded in a past study was below $5 \mathrm{mg} . \mathrm{L}^{-1}$ for the Ibai River as documented by Suratman et al. (2005) in a field survey conducted from August to December 2003.

Suspended solids were recorded highest for the Terengganu river, followed by the Ibai and Setiu Rivers (Table 2). A similar pattern was observed for ammonia concentration during the period of study. No drastic input into the Terengganu river basin was recorded; this result is in line with the low concentrations recorded in past literature with a mean value of $0.065 \pm 0.038 \mathrm{mg} . \mathrm{L}^{-1}$ (Suratman et al. 2015). This goes similarly with ammonia concentration where 0.04 to $0.24 \mathrm{mg} . \mathrm{L}^{-1}$ recorded in 2011 by Zaideen et al. (2017) for the Terengganu River. In the researchers' study, the ammonia concentration was measured to be in the range of 0.01 to 0.20 $\mathrm{mg} . \mathrm{L}^{-1}$. A similar finding of 0.01 to $3.4 \mathrm{mg} . \mathrm{L}^{-1}$ was reported by Laila et al. (2018) for the Ibai River.

\section{Concentration Levels of Caffeine}

Caffeine was detected in all $30(100 \%)$ samples collected during the period of study. The concentration levels of caffeine in Terengganu ranged from 384-406 ng. $\mathrm{L}^{-1}$ and 404-422

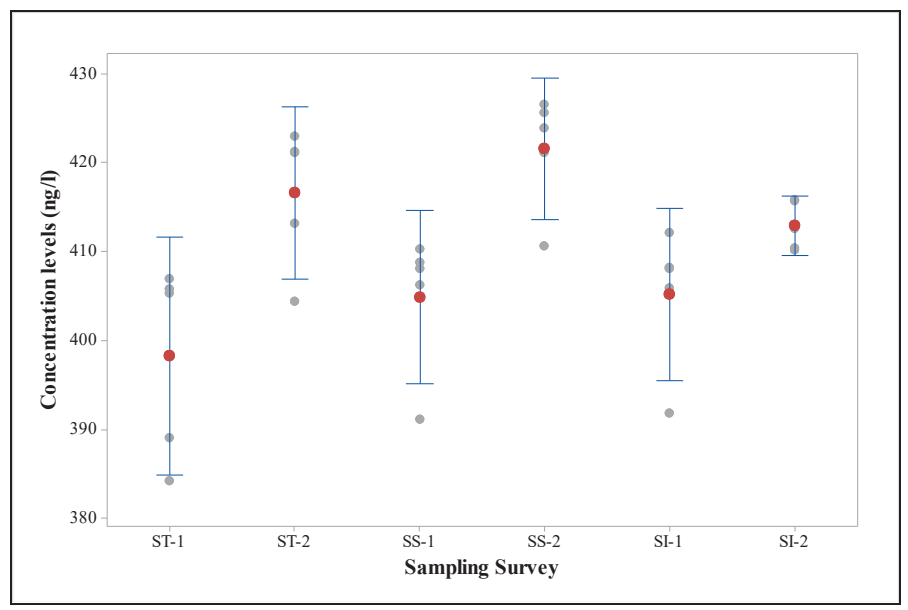

Fig. 2: Concentration range of caffeine residue found in rivers water. Red colour represents the median concentration. 
ng. $\mathrm{L}^{-1}$ for the first and second sampling surveys, respectively. Caffeine levels were found in the Setiu River to range from 391-410 ng.L $\mathrm{L}^{-1}$ and 410-426 ng. $\mathrm{L}^{-1}$ for both sampling surveys. Meanwhile, the concentration of caffeine in the Ibai River was recorded to be in the range of 391-412 ng. $\mathrm{L}^{-1}$ and 410-415 ng. $\mathrm{L}^{-1}$ for both sampling surveys (Fig. 2). The t-test revealed that the concentration levels found between the two surveys were significantly different, $\mathrm{p}<0.05$. This gave the idea that the anthropogenic input introduced into the riverine system has dynamic variations. Past studies by Al-Qaim et al. (2014) and Al-Qaim et al. (2015) mentioned that caffeine is one of the studied analytes with the highest concentration in Malaysia. However, the concentration of caffeine found in the Terengganu river was much lower than rivers situated in Negeri Sembilan (1644 ng.L $\mathrm{L}^{-1}$ ) and Selangor (351 ng.L$\left.{ }^{1}\right)$. The continuous inflow of human domestic waste into the river has led to higher concentration levels, especially in areas with a high density of human settlements.

Based on the cluster analysis, the samples were grouped into two clusters at $\left(\mathrm{D}_{\text {link }} / \mathrm{D}_{\max }\right) \times 100<0.90$. The formation of cluster SI-2 is believed to be due to a small range of concentration levels recorded during the second sampling programme (Fig. 3). The Ibai River basin is smaller than the other two rivers, thus it was believed that its dilution factor is weaker and thus, its concentration levels are rigid at a small range of variation. It can be observed that the concentration levels of caffeine residue vary for the other riverine systems (Fig. 2). The rain had occurred a day before the first sampling, thus it is believed that the river water was relatively diluted when the samples were taken. For the Setiu River, the similarity between both sampling surveys is high; this is believed to be due to the existence of the main source of contaminants which is human settlements which remained constant during the sampling event; additionally, no drastic new input had occurred.

\section{Risk Assessment}

An assessment of the RQs on the surface waters of the three rivers was conducted. The RQ values were calculated from the acute and chronic toxicity data for two trophic levels, namely Daphnia magna and Pseudokirchneriella subcapitata. The RQ values recorded ranged from 0.075 to 0.085 (Fig. 4 ). The findings revealed that the quality of surface waters has been affected by the emergence of caffeine; however, the risk of contamination had remained low. Hence, the contaminant has a minor influence on the ecological environment.

Despite its high frequency of detection in these river waters, caffeine has proven in past studies to only pose a low risk to the surrounding environment. For instance, a preliminary risk assessment on Brazilian surface waters revealed that the ecological risk remained low even with the high levels of detection in 175 samples (Sodre et al. 2018). The low risk status was also recorded for urban rivers in China. Although high concentration levels were recorded at 66-8571 ng. $\mathrm{L}^{-1}$, the RQ value calculated at 0.02 was far below the moderate risk level (Zhou et al. 2016). Low ecological risk of caffeine in the range of $<0.01$ to 0.07 in the Tama River and its tributaries was also recorded. The study had used this level to determine its toxicity value toward an alga species, Pseudokirchneriella subcapitata (Mano \& Okamoto 2016). In contrary, a high ecological risk of caffeine was measured in the Sinos River basin, Brazil where 5 out of 34 samples indicated RQ $>1$ toward the same species used in this study (Peteffi et al. 2018). Meanwhile, the medium risk

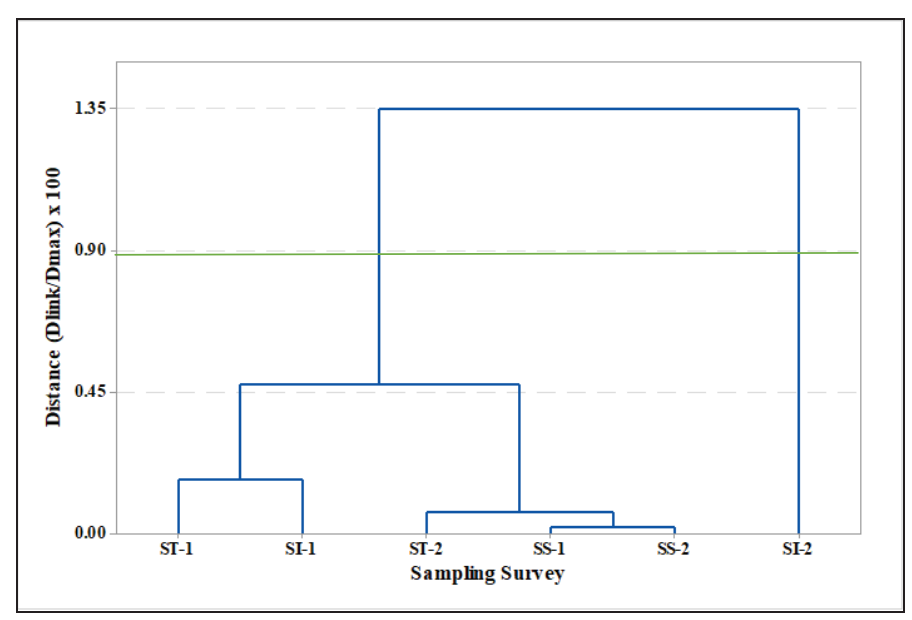

Fig. 3: Dendrogram of clustering the temporal similarities. 


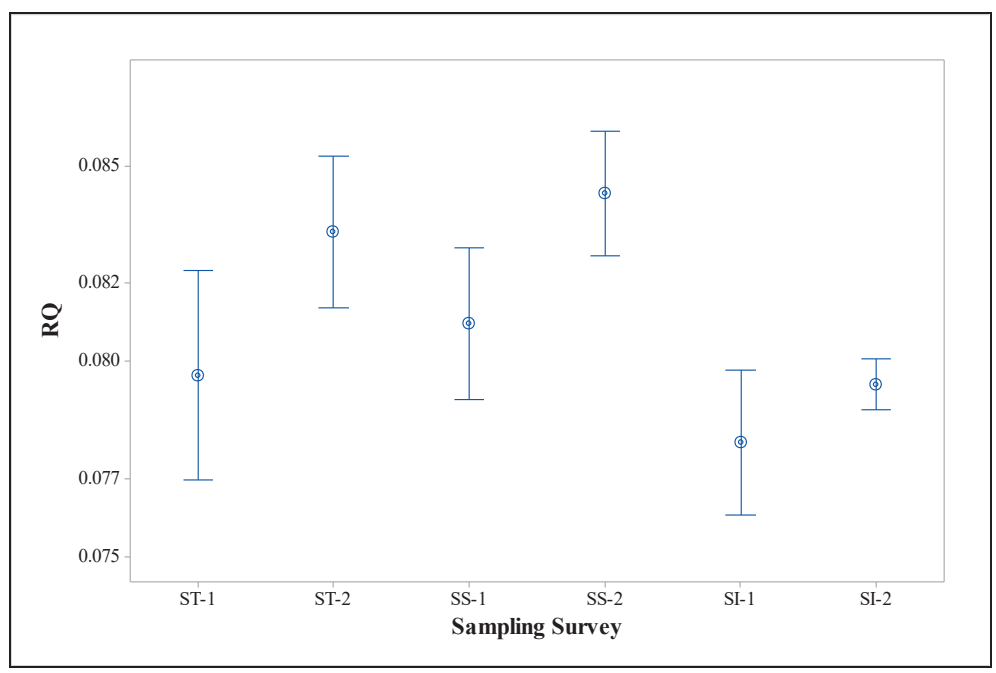

Fig. 4: Risk quotient of ecological assessment based on caffeine concentrations.

was reported in a study carried out by Komori et al. (2013) which dealt with environmental samples from rivers in Japan. The RQs calculated for caffeine present in the Terengganu rivers are not much different from other studies which also suggested a low chance of ecological impact for many pharmaceuticals based on acute toxicity tests. However, it is important to note that assessment of pharmaceutical residue using single compounds does not explain the real situation of environmental water health.

For human health risks, the RQs ranged from 0.19 to 0.20 for infants, 0.102 to 0.105 for children, and 0.093 to 0.097 for adults (Fig. 5). The DWEL values were calculated to be at $2120.53 \mu \mathrm{g} . \mathrm{L}^{-1}$ (infant), $4007.05 \mu \mathrm{g} . \mathrm{L}^{-1}$ (children), and
$4398.3 \mu \mathrm{g} . \mathrm{L}^{-1}$ (adult), respectively. In the present findings, the calculated RQ value of $\leq 0.2$ is considered to unlikely pose a risk to human health through water consumption. The RQ level for infants was at least 2.0 times greater than the RQ levels for adults. Similar patterns were reported in the literature, although the RQ values had varied depending on the concentration levels of caffeine (de Jesus Gaffney et al. 2015). Yang et al. (2017) found that infant exposure was recorded to be four times higher compared to adults; this was linked to infants' lower body weight. Although the finding of this study showed that the concentration levels posed no appreciable concern to human health, it, however, had only taken into account a single contaminant. Therefore, the water

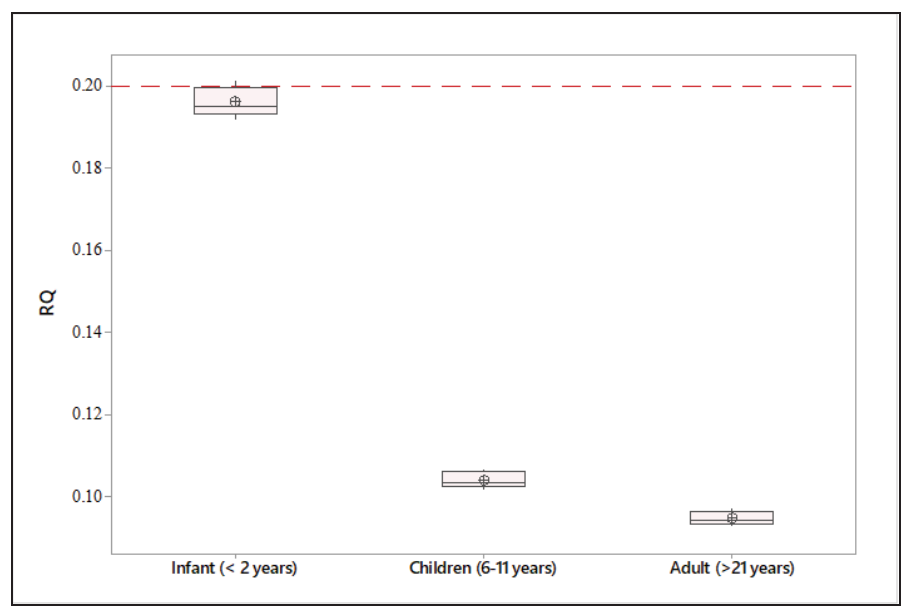

Fig. 5: Risk quotient of caffeine concentrations toward three life stages. 


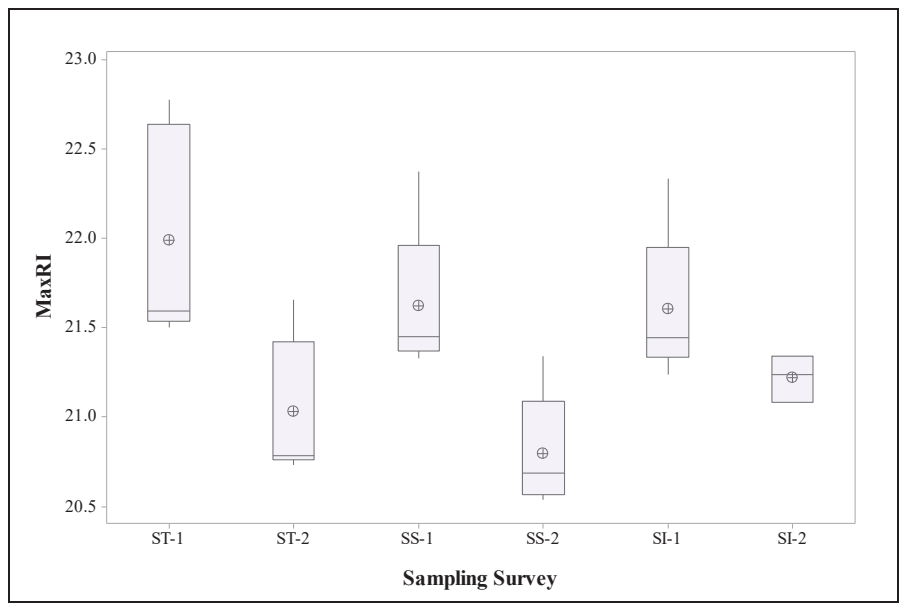

Fig. 6: MaxRI values of caffeine contamination in three Terengganu riverine systems.

quality as affected by contaminants is expected to be higher when pharmaceutical residues as a mixture are taken into consideration. Additional risks may be exhibited due to the presence of transformation products.

All sampling sites recorded MaxRI values (21.08-22.33) which fall under class II or the risk of sublethal effects to aquatic organisms (classified as ranging from $10<\mathrm{Max}-$ $\mathrm{RI}<100$ ) (Fig. 6). It is noteworthy to highlight here that the risk levels have the potential to increase when more input is introduced into the river system. Continuous discharge from anthropogenic sources into environmental waters will constantly replenish contaminant levels regardless of the amount of degraded caffeine, therefore creating a dynamic equilibrium. The results for the caffeine risk potential were lower than the one obtained in previous research conducted on the Henares-Jarama-Tajo river in Spain which recorded a MaxRI <10 (Fernández et al. 2010). However, a similar class to this research study results was reported by Letić et al. (2015) for the Danube River in Serbia. MaxRI values reported by authors ranged from 20.27-71.66.

\section{CONCLUSION}

This is the first scientific study that provides an estimation of both health and ecological risks associated with caffeine abundance in the river waters of Malaysia. The assessment on the ecological impact revealed that the emergence of caffeine residue in river waters have yet to cause acute toxicity towards aquatic organisms. In the case of river water used for human consumption, it has also proven unlikely to pose a risk on human health. The three rivers were grouped under class II for the maximum risk index. Although the occurrence of a single contaminant has been successfully evaluated, the real situation must take into account the presence of other pharmaceutical residues as a mixture of compounds. The present findings provide a good baseline data for further studies on contaminants of emerging concern since caffeine is frequently detected in Malaysian environmental waters.

\section{ACKNOWLEDGEMENTS}

The authors would like to thank Universiti Malaysia Terengganu for its financial support for the study under the analytical and environmental chemistry programme.

\section{REFERENCES}

Al-Qaim, F. F., Abdullah, M. P., Othman, M. R., Latip, J. and Afiq, W. 2014. A validation method development for simultaneous LC-ESI-TOF/MS analysis of some pharmaceuticals in Tangkas river-Malaysia. J. Brazil Chem. Soc., 25(2): 271-281.

Al-Qaim, F. F., Abdullah, M. P., Othman, M. R., Mussa, Z. H., Zakaria, Z., Latip, J. and Afiq, W. M. 2015. Investigation of the environmental transport of human pharmaceuticals to surface water: A case study of persistence of pharmaceuticals in effluent of sewage treatment plants and hospitals in Malaysia. J. Brazil Chem. Soc., 26(6): 1124-1135.

Al-Qaim, F. F., Jusof, S. H., Abdullah, M. P., Mussa, Z. H., Tahrim, N. A., Khalik, W. M. A. W. M. and Othman, M.R. 2017. Determination of caffeine in surface water using solid phase extraction and high performance liquid chromatography. Malays. J. Anal. Sci., 21(1): 95-104.

Buerge, I. J., Poiger, T, Müller, M. D. and Buser, H. R. 2003. Caffeine, an anthropogenic marker for wastewater contamination of surface waters. Environ. Sci. Tech., 37: 691-700.

Cantwell, M. G, Katz, D. R, Sullivan, J. C, Borci, T. and Chen, R. F 2016. Caffeine in Boston Harbor past and present, assessing its utility as a tracer of wastewater contamination in an urban estuary. Mar. Pollut. Bull., 108: 321-324.

de Jesus Gaffney, V., Almeida, C. M., Rodrigues, A., Ferreira, E., Benoliel, M. J. and Cardoso, V. V. 2015. Occurrence of pharmaceuticals in a water supply system and related human health risk assessment. Water Res., 72: 199-208.

Edwards, Q. A., Sergei, M. Kulikov and Leah D. Garner-O’Neale 2015. Caffeine in surface and wastewaters in Barbados, West Indies. SpringerPlus, 4.1: 57. 
Fernández, C., González-Doncel, M., Pro, J., Carbonell, G. and Tarazona, J. V. 2010. Occurrence of pharmaceutically active compounds in surface waters of the Henares-Jarama-Tajo river system (Madrid, Spain) and a potential risk characterization. Sci. Total Environ., 408(3): 543-551.

Ferreira, A. P. 2005. Caffeine as an environmental indicator for assessing urban aquatic ecosystems. Cad Saúde Pública., 21: 1884-1892.

Guzel, E.Y., Cevik, F. and Daglioglu, N. 2018. Determination of pharmaceutical active compounds in Ceyhan River, Turkey: Seasonal, spatial variations and environmental risk assessment. Hum. Ecol. Risk Assess., 1-16.

He, K., Echigo, S., Asada, Y. and Itoh, S. 2018. Determination of caffeine and its metabolites in wastewater treatment plants using solid-phase extraction and liquid chromatography-tandem mass spectrometry. Anal. Sci., 34(3): 349-354.

Komori, K., Suzuki, Y., Minamiyama, M. and Harada, A. 2013. Occurrence of selected pharmaceuticals in river water in Japan and assessment of their environmental risk. Environ. Monit. Assess., 185: 4529-4536.

Laila, O. M. A, Gasim, M. B., Toriman, M. E. and Hassa, M. A. A. 2018. The assessment of physico-chemical and biological water quality characteristics of the Ibai River between wet and dry seasons, Kuala Terengganu, Malaysia. J. Fundam. Appl. Sci., 10: 396-411.

Letić, N. N. G., Milanović, M. L., Milić, N. B., Miloradov, M. B. V., Radonić, J. R., Mihajlović, I. J. and Sekulić, M. M. T. 2015. Determination of emerging substances in the Danube and potential risk evaluation. CLEAN Soil Air Water, 43(5): 731-738.

Mano, H. and Okamoto, S. 2016. Preliminary ecological risk assessment of 10 PPCPs and their contributions to the toxicity of concentrated surface water on an algal species in the middle basin of Tama River. J. Water Environ. Tech., 14: 423-436.

Peteffi, G.P, Fleck, J.D., Kael, I.M., Rosa, D.C., Antunes, M.V. and Linden, R. 2018. Ecotoxicological risk assessment due to the presence of bisphenol A and caffeine in surface waters in the Sinos River Basin-Rio Grande do Sul-Brazil. Brazil J. Bio., 712-721.

Praveena, S.M, Shaifuddin, S.N.M, Sukiman, S., Nasir, F.A.M, Hanafi, Z., Kamarudin, N. and Aris A.Z. 2018. Pharmaceuticals residues in selected tropical surface water bodies from Selangor (Malaysia): Occurrence and potential risk assessments. Sci. Total Environ., 642: 230-240.

Ramaswamy, B.R., Shanmugam, G., Velu, G., Rengarajan, B. and Larsson, D. J 2011. GC-MS analysis and ecotoxicological risk assessment of triclosan, carbamazepine and parabens in Indian rivers. J. Hazard. Mater., 186: 1586-1593.

Sharma, B.M., Bečanová, J., Scheringer, M., Sharma, A., Bharat, G.K., Whitehead, P.G. and Nizzetto, L. 2019. Health and ecological risk assessment of emerging contaminants (pharmaceuticals, personal care products, and artificial sweeteners) in surface and groundwater (drinking water) in the Ganges River Basin, India. Sci. Total Environ., 646: $1459-1467$.

Sodre, F. F., Santana, J. S., Sampaio, T. R. and Brandão, C. 2018. Seasonal and spatial distribution of caffeine, atrazine, atenolol and DEET in surface and drinking waters from the Brazilian Federal District. J. Brazil Chem. Soc., 29(9): 1854-1865.

Subari, S. N. M, Osman, R. and Saim, N. 2017. Occurrence, source apportionment and environmental risk assessment of pharmaceuticals in Klang River, Malaysia. Pertanika J. Sci. Technol., 25: 119-128.

Suratman, S., Ali, A. and Lo, T. T. 2005. Determination of water quality index at Ibai River basin, Terengganu. Sains. Malays., 34: 55-59.

Suratman, S., Sailan, M. M, Hee, Y. Y, Bedurus, E. A. and Latif, M. T. 2015. A preliminary study of water quality index in Terengganu River basin, Malaysia. Sains. Malays., 44: 67-73.

Wu, J., Yue, J., Hu, R., Yang, Z. and Zhang L. 2008. Use of caffeine and human pharmaceutical compounds to identify sewage contamination. World Acad. Sci. Eng. Technol., 44: 438-442.

Yang, Y. Y., Toor, G. S., Wilson, P. C. and Williams, C. F. 2017. Micropollutants in groundwater from septic systems: Transformations, transport mechanisms, and human health risk assessment. Water Res., 123: 258-267.

Zaideen, I. M. M., Suratman, S. and Tahir, N. M. 2017. The evaluation of spatial variation of water quality in Sungai Setiu Basin, Terengganu. Sains. Malays., 46: 1513-1520.

Zhou, H., Ying, T., Wang, X. and Liu, J. 2016. Occurrence and preliminarily environmental risk assessment of selected pharmaceuticals in the urban rivers, China. Sci. Rep., 6: 34928. 